Rebecca M. Empson

University College London

e-mail: r.empson@ucl.ac.uk

Elizabeth Fox

University College London

e-mail: ehf991@gmail.com

\title{
Asset or Burden: The Ethical Calculus of Care in Ulaanbaatar's Urban Margins
}

\section{Abstract}

How do family relations change in the move from rural to urban living? What are the impacts of urbanisation on the domestic? Drawing on the ethnography of two families on the outskirts of Mongolia's capital, Ulaanbaatar, this chapter tackles the intersections of urbanisation and intergenerational care, charting the effects of rural-urban migration on family lives. Although their family structures differ, Tuya and Duya each find themselves shouldering the burden of being urban female breadwinners. To navigate conditions of profound economic precarity, they approach their families through a lens of economic-cum-moral strategizing, which we term a form of 'ethical calculus'. In the city, money becomes synonymous with care and family members are categorised according to a scale of asset-to-burden based on their capacity to support or increase the breadwinner's load. A focus on the work involved in such forms of care reveals a qualitatively different approach to family ties in urban Mongolia that pulls people in two directions. The first is the reconfiguration of marginal populations' relationship with the state to one that equates care with money. The second is the atomising pressure that life on Ulaanbaatar's margins puts on the hopes and capacities of household members.

Keywords: care, ethics, female breadwinners, interiority and exteriority, urban living, rural-urban migration, state, economy, home, pensions 


\section{Introduction}

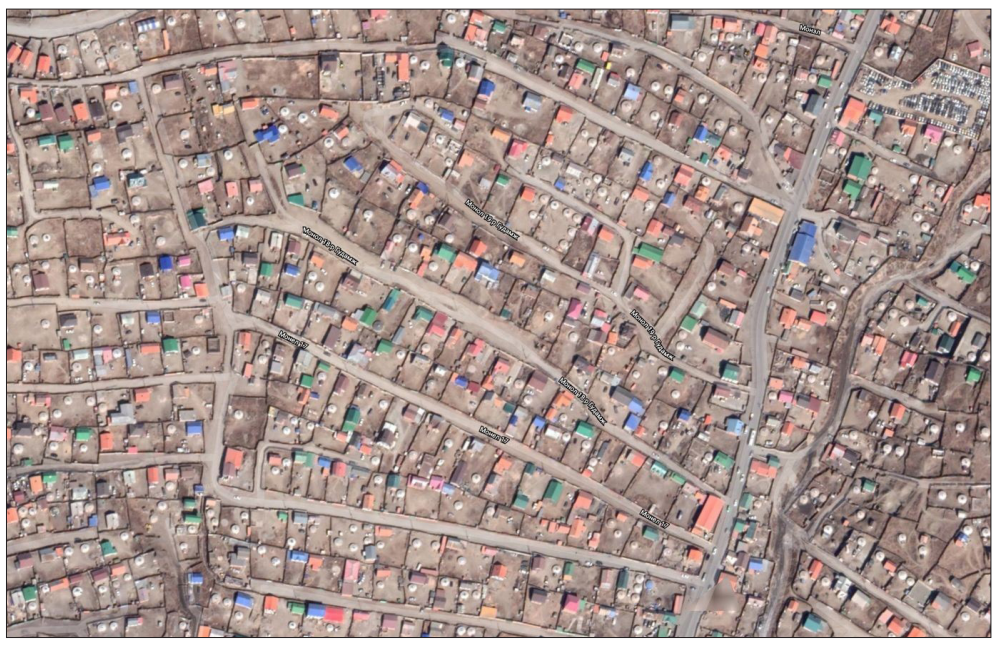

Figure 1. Ulaanbaatar Ger District [Photo taken from Google Earth]

Mongolia's capital city, Ulaanbaatar, is now home to almost half the nation's population of 3.3 million people (NSOM 2020). With the socialist-era city centre only built to accommodate around 500,000 inhabitants, the boundaries of the city have ballooned over the past three decades following the post-socialist loosening of restrictions on internal migration and the privatisation of urban land (Fernandez-Gimenez 2006; IOM 2018; Purevtseren et al. 2018). The areas that have grown to rapidly encircle the city through formal and informal processes of private land enclosure and acquisition (Plueckhahn 2017; Sneath 2006), primarily by rural-urban migrants, are called 'ger districts'. Named after the traditional Mongolian mobile felt dwelling, the ger, whose prevalence in these areas sets them apart from the apartment blocks and skyscrapers of the city centre, Ulaanbaatar's 'ger districts' almost encircle the urban core, blanketing the city's mountainous edges to the west, north and east and constitute over 80 percent of the city's built area (World Bank 2015: 1).

One might expect the ger districts to be made up entirely of white felt-wrapped, lattice-walled dwellings. Indeed, as the clichéd story goes, these districts are the result of former nomadic pastoralists abandoning life on the steppe, packing up the family ger, and relocating to the city outskirts. As with every cliché, this story contains elements of truth, but both the history of urbanism and the study of contemporary rural-urban migration in Mongolia reveals a far more complex picture (cf. Bruun, Narangoa 2006; Plueckhahn 2020; Plueckhahn, Bayartsetseg 
2018; Byambadorj, Amati, Ruming 2011; Fox 2019), one to which this paper seeks to contribute.

If, on the ground, tall fences (hashaa) obscure the view of life in these homes, the view from above immediately indicates that ger districts are not the inevitable result of the mobility of the ger. For, rather than a homogenous sea of white circles, the ger district homes appear from above as a patchwork of heterogenous splashes of colour - a neatly nested series of rectangular land plots. The bold blue, green and orange rectangles that stand out against the dusty ground of early spring in the photo above are the roofs of baishin: modest homes made of brick, wood, concrete blocks, or combinations of these materials. Despite their name, therefore, many, if not the majority, of the ger districts' homes are not Mongolian felt tents, but buildings. Looking at contemporary migration in Mongolia in relation to the house (baishin), rather than the ger, leads to important insights that subvert widespread assumptions regarding not only the theoretical intersections of mobility and architecture, but also the transformations taking place in concepts of home and family in urbanising Mongolia.

We trace the effects of urbanisation on Mongolian kinship through a comparative study of the urban lives of two middle-aged women whom we know well and whose lives appear strikingly similar to us in a number of ways. ${ }^{1}$ Tuya and Duya, each now live in the eastern ger districts of Ulaanbaatar, having been born in Khentii province and are the main breadwinners of their households. Despite many aspects of Tuya and Duya's lives being different, we chart underlying similarities in the ways the shift from rural to urban living affects how people conceive of their family members. Their approach can be characterised as a form of 'ethical calculus' (cf. Empson 2020) according to which they designate their children, partners and parents along a continuum from asset to burden. Subject to intense financial pressures, these urban breadwinners have little choice but to seek to relieve themselves of burdens and invest in assets (cf. Han 2012).

\section{Dwelling and movement in Mongolia}

While Mongolia has long been known as a nomadic society, recent trends in the anthropology of the country have highlighted many misconceptions associated with the concept of nomadism such as the idea that Mongolians move around continually or haphazardly in an unbounded, empty landscape. In con-

1 Pseudonyms are used to protect the anonymity of our interlocutors. The authors have each conducted long term fieldwork with the households of one of the women discussed: Fox with Duya and her family beginning in 2014 and Empson with Tuya and her family since 1999. The use of 'we' refers to Fox and Empson throughout, while the use of 'I' should be understood with regards to the ethnographic context. Where Duya's family is mentioned, 'I' refers to Fox; in discussions of Tuya's situation, 'I' refers to Empson. 
trast, scholars have focused on the significance of placemaking in Mongolia, the multiple material and symbolic ways that people are bound to particular places, and the specific and purposeful movements people make between places in order to make a living through mobile pastoralism (Humphrey, Sneath 1999; Myadar 2011). Such movements are made possible by the Mongolian ger which can be dismounted and re-erected in a matter of hours. But, beyond its remarkable flexibility as a dwelling, the same architectural form providing a breezy, shaded shelter in the summer and a well-insulated, life-saving sanctuary in the winter, the ger also affords domestic continuity. Domestic continuity, regardless of the ger's placement in the landscape, is produced by the fact that the world inside the ger remains constant and is materially reconstituted in the same way following every move.

The general material layout and conceptual schema of the Mongolian ger has remained relatively consistent over the centuries, despite a series of wider cultural and political changes (Paddock, Schofield 2015). Caroline Humphrey (1974: 1) has described the Mongolian ger as a "microcosm of the social world of the Mongols" for the way that it manifests and maintains social categories via the organisation of objects in space. A single-space structure without internal walls, the ger is conceptually subdivided into a series of realms: upon entering the ger, the upper (northern) portion furthest from the door is the mostrevered, while thelower(southern) half is the junior, lower-status portion; the left is the male 'ritually pure' side where guests are invited to sit, while the right is the female 'ritually impure' side reserved for household members. In accordance with this general schema, the ger as a domestic dwelling provides "a space in which every category of person or object in the nomad's world [can] be located" (Humphrey 1974: 1). Within the ger, people perform their social category (woman/man, guest/host) and status (senior/junior, adult/child) through their interactions with the objects and realms of their domestic living space. The consistency of the ger's organising schema and its capacity to adapt to Mongolia's shifts through state socialism to capitalist democracy, incorporating new material objects and technologies along the way, allows a shift in perspective regarding what moves and what stays the same even in 'nomadic' contexts. Reminiscent of what Morten Pedersen (2017) has called "moving to remain the same", we may consider the ger to be similarly stabilised every time it is moved. By being reconstituted according to the same schema wherever it is placed, it affords domestic continuity both in the sense of the domestic space and the social organisation of the people that dwell within its felt-wrapped walls.

If the ger represents a form of mobility that is ideally cyclical and repetitive (cf. Pedersen 2017), houses (baishin) in Mongolia can be linked to other forms of dwelling. However, far from representing sedenterization, our material suggests houses in Mongolia also move, but these migrations are generally non-cyclical and are associated with forms of social discontinuity and rupture. Such ruptures may precede the move of a house, such as the collapse of a family's pastoral life through the loss of herds in a deadly winter $(z u d)$, or be sought through the act of 
moving the house, as when a family consolidate their status as Ulaanbaatar-ites by having their countryside baishin demounted and moved to the city, or indeed the former may lead to the latter.

Tuya and Duya's cases are interesting because both now live in the Ulaanbaatar ger districts in houses that once stood in the countryside. The relocation of gers to Ulaanbaatar is a well-known phenomenon, but the moving of baishin has not yet been analysed. In this paper we reflect on the conceptual possibilities of gers and baishin both in terms of mobility and the constitution of household forms. We suggest that while both gers and houses prove to be mobile in Mongolia, in the context of rural-urban migration houses do not appear to afford the same kinds of social continuity as the ger may when moved in the context of mobile pastoralism. However, rather than seeking to make a materialist argument that suggests an absolute difference between gers and houses and the forms of domestic sociality they produce (one that would clearly fail in light of the struggles of the many rural-urban migrants in Ulaanbaatar living in gers), we instead build on the anthropological use of the house as a "theoretical jumping off point" from which to reflect on the interrelation between households and the structures they call home, examining "links between their architectural, social and symbolic significance" (Carsten, Hugh-Jones 1995: 2). Drawing on the relocations of Duya and Tuya's houses, we offer new material on kinship and urbanisation in Mongolia by exploring how, in the move from rural to urban life, Duya and Tuya's houses have come to shelter different people who are both valued and can create value in different ways. $^{2}$

\section{Female breadwinners: Duya and Tuya}

Born to a prosperous herding family in eastern Mongolia in 1973, Duya was seventeen when the democratic revolution swept through the Mongolian People's Republic, bringing new personal freedoms but also an end to the socialist state structures that had supported her life and shaped how she had imagined her future up until that point. Educated by the state, she had just completed her training as a flour technician in preparation for a job in a factory when Mongolia's manufacturing industries collapsed. Still considered a minor, she was also left out of the post-socialist redistribution of state assets to private citizens. With few options,

2 The house itself, as 'part' of the kinship unit (one that has furthermore participated in the family's rural to urban migration) and not just its 'container' could also be incorporated into the analysis of household assets and burdens. Tuya and Duya's baishins benefit them and their families in many ways, but also require care that entails a series of costs, such as that of coal or other heating sources, the constant need for repairs and those associated with establishing land and home ownership etc. At present, this discussion is beyond the ethnographic scope of the article but remains a question for future reflection. 
at eighteen she married a local man eight years her senior and within a few years had given birth to two daughters. Although her husband was hardworking, he was prone to jealous rages. Following one such incident, Duya took her daughters and returned to her family in the district centre. There, she reconnected with Dashaa, a classmate of her older sister, and soon became pregnant with a son. Since then, Duya and Dashaa have lived together, raising Duya's two daughters, and their three subsequent children, two boys and a girl.

Once independent herders, a series of events including a $z u d$ that killed much of their herds, a theft that wiped out their savings, a period of depression following the death of an infant son, an unfortunate period as herders-for-hire, in combination with the aspiration to give their children access to an urban education, saw Duya and Dashaa move multiple times between countryside and city between 1999 and 2010, each time losing more in the process. Now settled in the eastern edge of Ulaanbaatar, they are held in the city by webs of debt and aspiration. Having worked a series of jobs over their years in the city, including a short period for Duya as a trader travelling between the Chinese border, Mongolian countryside and Ulaanbaatar, Duya has spent the last eight years employed as a dormitory cleaner for a private university in the city. The job provides a low but regular salary, access to forms of credit, such as salary loans, and vital social insurance stamps that should allow Duya to retire with a pension.

Only a kilometre or so away, lives Tuya, a 49-year-old unmarried woman also from Eastern Mongolia. Tuya and her 16-year-old son live together with her almost completely blind mother. Tuya works full-time at a state nursery on the outskirts of Ulaanbaatar, where working parents leave their children in the morning around 7.30 or 8.00 a.m. and sometimes do not return until 10.00 p.m. After this very arduous job, Tuya walks home and cooks, cleans and catches up with her mother, who never leaves the yard they live in. She continues to work, in spite of various health conditions because she is collecting state-stamps in order to claim her pension in a few years' time. The lure of the pension is enough to put her current ailments and troubles on hold, sacrificing present hardships for others and for a future she can hope for.

Tuya's parents were well-respected Buriad elders who held positions of leadership in the cooperative of their small rural Eastern Mongolian district centre during the socialist period. She was their youngest child. When she was 34, she had a son with man whose identity she never divulged. As the former postal lady who managed the only telephone line in her district centre, Tuya knew everyone's news and was the absolute centre of people's lives in the countryside. She left the post office, a government institution with government-appointed employees, because of the party change when the Democratic Party came into power in 2003; she had been a staunch Revolutionary Party supporter all her life. She sold her animals to fund her new life and, seven years ago, moved to the city and paid for an accountancy course. Once completed, she could not find a job because, as she com- 
mented, she was 'too old, too short and too fat'. Taking out a loan, she retrained as a kindergarten teacher and got a job, first at another kindergarten, and then at a newly built state-run kindergarten close to her current house.

Historical accounts of gender and women's roles in Mongolia often emphasize their relative equality (at the very least in comparison to other societies in the region) and the value placed on women's capabilities. Mongolian women held their own places in their home by right, not repression (Humphrey 1992: 183), owned property and livestock (Humphrey 1992: 184), and their physical strength was highly praised. Furthermore, it has not been rare for women to be household heads, carrying out all the productive tasks of a herding household, whether as single mothers, such as during the $17^{\text {th }}$ century when nearly one third of the male population had become Buddhist monks (Tumursukh 2001: 124), or for the duration of men's absences from home (Humphrey 1992: 180). During Mongolia's seventy years as a socialist state, concepts of gender equality were transmuted to fit socialist social models: "All able-bodied men and women were employed in the formal economy, all children were provided with compulsory general education, and many women entered higher educational institutions" (Tumursukh 2001: 125).

Today, Mongolian women are more highly educated than men and, while this does not translate into higher labour force participation nor better earnings on a national scale (NSOM 2018: 38), among the poor urban families in the ger districts it is not uncommon for women to be primary breadwinners (Benwell 2006). ${ }^{3}$ The reasons for this include the higher numbers of women who work as microentrepreneurs in the informal sector (UNIFEM 2001: 46), the fact that women's skills tend to transfer more easily from rural to urban life (Fraser 2021: 16), and the types of employment that are available in the urban outskirts, such as cleaning, catering, retail support services and teaching which are highly gendered in Mongolia (Ariunzaya, Munkhmandakh 2019; Benwell 2006: 116-118). Female headed households, while fairly common, are more likely to be under financial stress, with a third of urban female headed households being classed as poor (Khan et al. 2013: 14). Female breadwinners not only earn less than men, but lead households that are more likely to have male dependents: strikingly, "working age males account for about a third of dependents in female headed households... with a significant portion of these over the age of 30" (Khan et al. 2013; see also: NSOM 2020: 14). Furthermore, these male dependents do not appear to lessen the domestic labour of female breadwinners; women report spending as much time on household and care duties (double that of men) whether employed or not, carrying the infamous "double burden" (NSOM 2020: 16). Tuya and Duya's cases speak to these realities of being a female breadwinner in a multigenerational household with a number of working-age dependents.

3 The employment rate for men in urban areas is 11.8 percentage points lower than that of men in rural areas (NSOM 2020: 13). 


\section{Multigenerational households}

Both Tuya and Duya live in fenced enclosures that house multiple generations and structures. ${ }^{4}$ In Tuya's yard there is also her eldest sister's house whose household is composed of her and her husband, their two daughters and a cousin. The sister's house was brought to the city from the countryside several years ago, but it was only last year that Tuya was able to raise the cash to hire a vehicle and the men to help load and transport her house from the countryside to this plot. As her house was moved from the countryside to the city it came to serve a very different purpose and house a different set of people. In the countryside it was a symbol of independence from her parents, a sign that she had made enough of herself, despite having a son on her own, to move on. It stood within the same plot as her parents' house, but at some distance and could be approached via a different gate from theirs. Now, it has come to be a haven for not just her, but also for her mother.

When I first stepped over the threshold of her house in the city, she lamented that she had not been able to invest sufficiently in its upgrade as a 'city house' due to various financial burdens. As far as I could notice, however, it was very different from the simple wooden structure of the countryside that I was familiar with, and full of the trappings of a 'modern' city life. It had plastic double glazed windows, nylon curtains, wall paper, defunct washing machine (now used as storage space), large television on an elaborate stand in the place of an alter, and plastic vinyl flooring, while the window sills contained various creams and medicines, and the electric sockets sprung forth with multiple adaptor cables and extension leads.

Tuya's mother spends her days confined in this small one-roomed house that Tuya brought from the countryside. She lives, sleeps and eats here, but she has not ventured out of the fenced enclosure since the truck delivered her two years ago from her home in the countryside. She arrived against her will, after the death of her husband, pressured by her family to stay with her youngest daughter in the city. She suffered from car sickness and had to be carried from the car after 18 hours of non-stop vomiting. Tuya's son wants to leave the house and live in an apartment as soon as possible. He is aspirational and constantly dissatisfied with what his mother provides. She wants her son to 'go to a good school, to graduate well and go to university'.

Unlike Tuya who never married, Duya lives with her second husband Dashaa. Dashaa, however, has only a basic primary school education, and has struggled to earn money to support the family. He used to find work in the construction sector during the summer, but a fall from a roof led to a broken leg and being employed by small firms that never have the cash to pay the salaries promised led him to look elsewhere. During autumn and winter, he finds occasional work at a nearby

According to the 2020 census, the number of composite households in urban areas is 3.9 times higher than in rural areas (NSOM 2020: 9) 
coal depot, but workers do not receive a salary for their hours labouring in the freezing cold and swirling black dust, they are merely paid a small cut when someone visits the depot and purchases coal. Although Duya's husband Dasha distinguishes himself from other men that have lost all hope and turned to alcohol, Duya still complains that she returns from work only to face household chores Dashaa should have taken care of while she was earning the money that puts food on the table. Furthermore, when Dashaa occasionally indulges in gambling with his nearby brothers-in-law, it leads to furious arguments regarding his role in and contribution to the family.

Apart from the youngest daughter who is in primary school and the eldest who has married and left the household, the family's children, aged 16, 18 and 23 are caught between pursuing their education in hopes of future opportunities or contributing to the household's finances in the present as best they can. More often than not, they end up wedged in between, abandoning their studies for fleeting employment opportunities that do not end up delivering the promised compensation and, in doing so, falling behind. Duya once told me that as long as a family has one talented child, they will be alright. The family placed much of their hopes on the eldest son, who earned a prestigious place in the Mongolia National University. The fees for his studies, however, far outstrip the family's earnings and he struggles to progress as they often cannot afford to give him money for bus fares or food during the day. Their middle daughter also earned a higher education, graduating as a teacher from a small private university, but she ended up pregnant and so could not take up the job she had arranged following her graduation. The youngest son is studying welding at a technical college and may make a good living when he qualifies, but for now he remains a student.

Duya, Dashaa, their four children and their granddaughter live together then, like Tuya's family, in a wooden house that once stood in the countryside. Like Tuya, having found a way to establish themselves, however precariously, in Ulaanbaatar, they arranged transportation for their countryside baishin and had it reassembled in the plot they had secured in the ger district. The tiny house consists of two 'rooms', one that contains two beds and the main living area with the household stove, low table and chest freezer. Unlike a ger, the furniture and arrangement of the objects in the house were constantly being rearranged. At times the television (a staple in all Mongolian homes, urban and rural) was placed in the main room, but often it stood in the west room. The household stove and chimney pipe were one year moved from one side of the room to the other and the mounted kitchen cabinets were also taken down and reinstalled on another wall. While food preparation always took place in the main room which had a vinyl floor (as opposed to the carpet in the west room), people might sleep in either room. Duya, Dashaa and their youngest daughter usually slept together on mats on the floor of the main room, with the other children in the west room, but sometimes one bed from the west room was moved into the main room. 
The frequent changes to the domestic layout echoed those that take place in the activities of the household members. Some are cyclical and regular, such as the move between term time and school holidays; the academic calendar shaping both the children's studies and Duya's work in the university dormitory. Other changes are sudden or fleeting like work opportunities for Dashaa and the older children that might come and go in day. The one constant remained Duya's precious job.

\section{Ethical calculus: asset or burden?}

Being the primary breadwinners puts unrelenting pressure on both Tuya and Duya that none of their family members can yet relieve. Primarily they are made to perform regular ethical-cum-economic calculations, weighing up what each family member can contribute to their household in lieu of others benefiting. This budgeting seemed to happen, for both women, on quite a regular basis, due to internal and external fluctuating conditions, as well as a complex of loan repayments and options for new loans arrangements arising. In this regard, while some aspects of these household's financial cycles remain similar between the city and the countryside - i.e. children's school, Lunar New Year, summer break, etc., city dwellers become detached from animal-based seasonal cyclical events and also follow very different cycles. ${ }^{5}$ Living under unrelenting financial pressures has transformed their relationships with their family members who each come to sit on a spectrum from asset to burden. ${ }^{6}$ By late summer, Tuya and Duya begin the work of projecting what the year will hold in terms of economic demands. With different family members living with them, or asking to be included in their household, they have to assess how they might go about fulfilling the year's economic burdens, allocating duties and responsibilities to some and granting expenditures to others.

In the countryside, those who comprise a household changes seasonally, depending on the kind of duties and tasks at hand in a particular location. Hence, winter encampments are often sparsely populated but summer encampments may house several generations who are needed to help with processing products and looking after young animals. In contrast, households in the city are often relatively stable throughout the year in terms of the number of people who reside there, apart from in the summer months when many travel to the countryside. It is in this sense that we might say that while physically remaining the same structure (having been brought by truck from the countryside to the city in both cases),

${ }_{5}$ Although not completely because city residents do travel to the countryside to help with idesh (slaughter/grass cutting/shearing wool), but their capacity to do that becomes unpredictable and depends on their finances - whether they can find a way to travel to the countryside.

6 We use the terms asset or burden here in a purely economic sense but of course ethical and subjective decisions also come into play. 
the house has come to house people in a different way when relocated to the city. In many ways this is because the 'assets' attached to a house in the city (mostly people and objects), differ from those in the countryside (i.e. animals). With the move from rural pastoralist to urban lifestyles, household members - perhaps working-age men in particular - experience (often negative) shifts in the types of opportunities they have to contribute to household prosperity. While men, like Dashaa, can and do carry out household duties or bring in occasional income, and children do their best to study, find independent sources of pocket money, and represent future potential, their impact is limited and furthermore less unified than the contributions they might have or once did make in their respective rural households.

This leads to the somewhat strange situation that people like Duya and Tuya have to assess their extended family members with an almost clinical economic eye, anticipating who will be a burden and for what future rewards may they occupy this position. In fact, one of the major ways that kin members show their care and support for each other is through the gifting of money - to attend university, for school books, for medicine and help. Networks of familiarity (tanil takh) facilitate such flows, but can equally dry up or run out. Tuya and Duya's calculations aim to keep these flows going, making sure that those that can are working to produce cash, or are mobilizing their collateral in order to loan it.

Tuya, for example, works as a kindergarten teacher to fund a series of impending expenditures: her son's university education and multiple debts which she has incurred to fund the relocation of her house, and the kinds of technology that they use inside. Tuya's mother, now mostly a financial burden, has worked most of her life. Her regular pension has been used several times over as collateral to take out various formal and informal loans to fund medical procedures for Tuya's sister and herself, school and university fees, and forms of subsistence. She has, in a sense, sacrificed her future life (her pension) for the present lives of her children and grandchildren. Now unable to offer more, she is totally dependent on them. They, in turn, are indebted to her for the money she was able to provide, but they are unable to repay this in cash, only in care. Tuya's son contributes by collecting plastic bottles from the roadside and river beds which can be returned for a small fee. They also stockpile coal which can be sold for a higher price informally when stock becomes scarce. Most of her jewellery has been pawned and she is waiting to be able to buy it back when her salary begins again.

The status of each family member as asset or burden shifts over time. Tuya's mother was an asset with her pension against which loans could be granted but changed to a burden when this ceased. Her son absorbs many financial expenditures and will do so for some time ahead. While constituting a burden in many ways, children bring vital money to poor households in the form of 'children's money' a monthly direct cash transfer paid to all Mongolian families. Only a mere 20,000 tugrugs, in Duya's case, on aggregate the additional money makes a mate- 
rial difference to the family's survival (Fox 2020). ${ }^{7}$ As the payments stop when a child reaches eighteen, that is also the age when the asset-burden balance may have to be recalculated.

For a period of time, Duya's unmarried daughter looked like she was about to shift from a burden (i.e. student) to an asset (i.e. teacher). Having helped support her through university, Duya was optimistic that her daughter would soon compensate her by earning a decent salary which would be into the family finances. When, however, September came and, instead of starting work in a school her daughter was giving birth to a child whose father did not acknowledge her existence, Duya was overcome with rage. Although she repeated the Mongolian proverb that 'no person is too many', the reality of the situation was that the new child would become another mouth for Duya to feed on an already over-stretched budget and force an adult to stay at home out of work, just as Duya's eldest daughter was becoming old enough to require less care. Duya began to hope even more fervently that her daughter would just find someone to marry. If she could do that, then responsibility for her and her child would be shifted away from Duya entirely. Just over a year later, her daughter admitted that she was pregnant again, this time with a young man who seemed amenable to marriage. Duya pushed hard for the marriage, even if privately she doubted that the young man, a poet, would be able to support her daughter. When the time for the engagement came and passed, she sent Dashaa to the man's parents to pressure them to take her pregnant daughter, which, eventually, they did.

\section{Working toward the State Pension and its collateral}

Duya's attitude towards her family members and the ethical calculus she is forced to make in terms of categorising them as either a burden or asset is driven not only by the family's poverty, but also intersects with the way each person is viewed by the state. The view of the state leaves little room for aspiration, classifying all her children, except the youngest girl as 'working-age adults'(i.e. 15 and above) and denying the family assistance on the basis that the children and Dasha should be working. The reality of the lack of job opportunities in the ger districts or the idea that studying is a worthwhile investment in one's future does not enter into the equation.

The light at the end of the tunnel, for Duya and Tuya, is retirement, something they dream of often. ${ }^{8}$ The path to this dream is paved by the social insurance stamps they collect in their employment record. As a form of compensation for

7 In 2018, social transfers, such as child(rens) money, accounted for one third of a poor household's total income (NSOM 2018: 35).

8 It is important to note that the forms of occasional work Dashaa does do not earn him stamps in a social insurance book. 
the 'lost years' in the wake of the democratic revolution, the state gave people like Duya ten years of stamps. As such, and also taking into account her being a mother of five, she should be able to retire at 55 . Thus, she works tirelessly, collecting stamps and waiting for that day to come. Tuya is also collecting state stamps in her social security book (niigmiin daatgalyn devter) in order to qualify for a pension in a few years' time. Her mother's pension is now completely non-existent, having been collateralised so that bank loans can be taken out against it for several years to fund her grandchildren's education and the medical care that allowed her now deceased daughter to be taken abroad for treatment. Despite a slew of medical problems, Tuya is very keen to avoid missing work at all costs in order to make sure that she has the necessary sequence of state stamps in her social insurance book to qualify for a national pension and that she has the funds necessary for her son to graduate that summer.

One detrimental outcome of working toward the idea of a better life with a state pension is the collateral fall-out this has on one's body. Both women suffer from poor health, and are unable to rely on the state for care. Two years ago, Duya was diagnosed with cancerous polyps in her womb and had to have surgery to remove them. For the family, the fear that Duya would not be able to return to work, let alone cover the cost of the treatment, wreaked havoc. With no one else able to shoulder the burden of breadwinner, they waited anxiously for her to recover, which thankfully she did. The following year, however, Duya was temporarily fired from her job. University bosses wanted to replace her and her colleagues with their own relatives. In a job market like Ulaanbaatar's where unskilled workers are ten a penny, a steady cleaning job like Duya's is a prime employment opportunity. Fortunately, however, the relatives ended up not taking the position and Duya was asked to return. Added to her workload, however, was the annual Autumn refurbishment of the university dorm, an arduous task for Duya and her two similarly middle-aged colleagues which the university required of them without providing any personal protective equipment for the paint dust and mould the women inhale as they sand and resurface the ceilings and walls,.

Tuya's life as the household breadwinner likewise rests on a tight shoestring, something she balances with great care and attention. Recently, however, this balance had almost fallen apart, for, like Duya, she was also diagnosed with a cancerous tumour and had to have her womb removed. The operation was carried out in a hospital in a provincial centre (because it was cheaper than in the city) and she only stayed for the minimum number of days in order to save money. After the operation she spent a month recuperating, whereupon they took out her stitches and discharged her. Once home, she went to a hospital in Ulaanbaatar every day to have the wound cleaned and redressed. To raise funds for her ongoing medication she had to pawn her jewellery. In spite of her health, Tuya planned to return to work only a few weeks after the surgery. She was anxious to get better so she 
could start working to pay off her loans and raise the funds for her son's high school graduation, university fees, and laptop.

Significant health scares like the ones experienced by Duya and Tuya lay bare the extent of the pressure on their families, a pressure that is centred on these breadwinners and the question of how much their bodies can take. It remains to be seen whether the two women can continue to carry the weight of their burdens long enough for some to eventually transform themselves into assets.

\section{Concluding remarks}

This article has shown that houses brought from the Mongolian countryside to Ulaanbaatar city can be seen "..with the people who inhabit them as mutually implicated in the process of living" (Carsten, Hugh-Jones 1995: 45), shifting in value and use. As with the people engaged in the ongoing urbanisation of Mongolia, particularly the growth of the capital city and its ger districts, people's dwellings are likewise being moved and changed. Some architectural forms, like the ger, have long histories of movement and well-established internal schema that bind material and conceptual arrangements in the service of household continuity, while others, like the baishin, are being subject to new migratory forces and foster reflection on similarly less stable and more transformed household dynamics.

While a physical house may be moved from countryside to city, once re-established in Ulaanbaatar's ger districts it affords a different kind of household, with kin relations reconfigured by the conditions of urban living. Seemingly familiar from the outside, the internal world of ger district homes is shaped by the economic contributions people are able to broker with the outside world and the way such contributions shape the relations of those they live with. Through our focus on the experiences of two families, we draw attention to the shift in the types of roles and opportunities for household members that follows the urban relocation of the house and the emergence of new ways that family members are perceived by their respective breadwinners. ${ }^{10}$

For Duya and Tuya, their urban households have become reconceptualised in terms of the way different inhabitants are able to contribute financially. As they navigate a hostile terrain of limited opportunities, moving between life stages, pursuing studies, finding part-time work, or becoming pregnant, for example, household members move along a continuum between asset and burden. With family members categorised according to a scale of asset-to-burden based on their capacity to support or increase the breadwinner's load, money becomes very

${ }^{9}$ Indeed, parallels emerge between stable exteriors and fluctuating and changing interiors for both people and houses as they relocate and migrate over time.

${ }_{10}$ Indeed, parallels emerge between stable exteriors and fluctuating and changing interiors for both people and houses as they relocate and migrate over time. 
much synonymous with care, both in the sense of contribution to the breadwinner's burden and the type of care breadwinners themselves provide. Focusing on Tuya and Duya's ethical calculations reveals a qualitatively different approach to family ties in urban Mongolia that pulls people in two directions. The first is the pressure this puts on household members and the second is the reconfiguration of marginal populations' relationship with the state to one that equates care with money. It is, thus, left to Tuya and Duya to work resolutely to support their families and collect social insurance stamps in hopes of one day retiring with pensions, even though the unrelenting pressure to provide and its deleterious effects on their health may yet cut short their dreams.

\section{Acknowledgements}

Elizabeth thanks the Economic and Social Research Council for funding her MRes and $\mathrm{PhD}$ at UCL and the Mongolian and Inner Asian Studies Unit, University of Cambridge for the early career researcher grant that supported the writing of this article. She also thanks Duya, Dashaa, their family and all her interlocutors in Mongolia without whom this research would not be possible and Rebecca Empson for being an exemplary supervisor and mentor over the past decade. Rebecca thanks the European Research Council funded 'Emerging Subjects' research project (ERC-2013-CoG, 615785, Emerging Subjects) based at UCL and NUM, from 2014 to 2019 and all the affiliated researchers and people attached to that project at different stages for the exciting and productive research community it afforded. She also thanks Duya, her mother (and her now past father) and son, whom she has known since 1999, and UCL Press for allowing her to reproduce some parts from her book Life in the Gap: Subjective Lives and Economic Transformations in Mongolia (2020). Working with Liz Fox on this article and over the past few years has been a huge privilege. Both authors thank the anonymous reviewers for their comments and suggestions.

\section{Bibliography}

Ariunzaya A., Munkhmandakh M.

2019 Women and the Future of Work in Mongolia, Ulaanbaatar.

Benwell A.F.

2006 Facing Gender Challenges in Post-Socialist Mongolia in: O. Bruun, L. Narangoa (eds.), Mongols from Country to City: Floating Boundaries, Pastoralism and City Life in the Mongol Lands, Copenhagen, pp. 110-139. 
Bruun, O., Narangoa, L.

2006, A New Moment in Mongol History: The Rise of the Cosmopolitan City in: O. Bruun, L. Narangoa (eds.), Mongols from Country to City: Floating Boundaries, Pastoralism and City Life in the Mongol Lands, Denmark, pp. 1-20.

Byambadorj T., Amati M., Ruming K.J.

2011 Twenty-First Century Nomadic City: Ger Districts and Barriers to the Implementation of the Ulaanbaatar City Master Plan, "Asia Pacific Viewpoint", vol. 52 (2), pp. 165-177.

Carsten J., Hugh-Jones S.

1995 Introduction in: J. Carsten (ed.), About the House: Levi-Strauss and Beyond, Cambridge, pp. 1-46.

Empson R.

2020 Life in the Gap: Subjective Worlds and Economic Transformations in Mongolia, London.

Fernandez-Gimenez M.E.

2006 Land Use and Land Tenure in Mongolia: A Brief History and Current Issues. USDA Forest Service Proceedings, RMRS-P-39.

Fox E.

2019 Between Iron and Coal: Enacting Kinship, Bureaucracy and Infrastructure in the Ger Districts of Ulaanbaatar, Doctoral thesis (Ph.D), UCL (University College London).

2020 Child Money and Food Stamps: A Comparative Analysis of Mongolian Welfare Programmes in the Ger Districts of Ulaanbaatar, "Zeitschrift für Sozialreform”, vol. 66 (4), pp. 499-524.

Fraser R.

2021 In-Between the Rural and the Urban: Skill and Migration in Ulaanbaatar's Ger Districts, „Ethnos”, vol. 86 (4), pp. 1-16.

Han C.

2012 Life in Debt: Times of Care and Violence in Neoliberal Chile, California.

Humphrey C.

1974 Inside a Mongolian Tent, "New Society", 31, pp. 1-3.

1992 Women and Ideology in Hierarchical Societies in East Asia in: S. Ardener (ed.) Persons and Powers of Women in Diverse Cultures, Oxford, pp. 173-192.

Humphrey C., Sneath D.

1999 The End of Nomadism? Society, State and the Environment in Inner Asia, Cambridge.

IOM (International Organization for Migration)

2018 Mongolia: Internal Migration Study. Ulaanbaatar.

Khan T. et al.

2013 Mongolia: Gender Disparities in Labor Markets and Policy Suggestions. Washington.

Myadar O.

2011 Imaginary Nomads: Deconstructing the Representation of Mongolia as a Land of Nomads, "Inner Asia", 13, pp. 335-362.

NSOM (National Statistics Office of Mongolia)

2018 Mongolia Poverty Update 2018: Main Report of "Household Socio-Economic Survey 2018", Ulaanbaatar. 
20202020 Population and Housing Census of Mongolia: Summary, Ulaanbaatar. Paddock Ch., Schofield J.

2015 Authenticity and Adaptation: The Mongol Ger as a Contemporary Heritage Paradox, "International Journal of Heritage Studies", vol. 23 (4), pp. 347-361.

Pedersen M.A.

2017 Moving to Remain the Same: An Anthropological Theory of Nomadism in: P. Charbonnier, G. Salmon, P. Skafish (eds.) Comparative Metaphysics: Ontology After Anthropology, London, pp. 221-245.

Plueckhahn R.

2017 The Power of Faulty Paperwork: Bureaucratic Negotiation, Land Access and Personal Innovation in Ulaanbaatar, "Inner Asia", vol. 19 (1), pp. 91-109.

2020 Shaping Urban Futures in Mongolia: Ulaanbaatar, Dynamic Ownership and Economic Flux, London.

Plueckhahn R., Bayartsetseg T.

2018 Negotiation, Social Indebtedness, and the Making of Urban Economies in Ulaanbaatar, "Central Asian Survey", vol. 37 (3): Capitalism in Mongolia, pp. 438-456.

Purevtseren M., Tsegmid B., Indra M., Sugar M.

2018 The Fractal Geometry of Urban Land Use: The Case of Ulaanbaatar City, Mongolia, "Land", vol. 7 (2), pp. 67-91.

Sneath D.

2006 Transacting and Enacting: Corruption Obligation and the Use of Monies in Monoglia, „Ethnos: Journal of Anthropology”, 71(1), pp. 89-112.

Tumursukh U.

2001 Fighting Over the Reinterpretation of the Mongolian Woman in Mongolia's Post So-cialist Identity Construction Discourse, "East Asia: An International Quarterly", vol. 19 (3), pp. 119-146.

UNIFEM (United Nations Development Fund for Women)

2001 Women in Mongolia:

Mapping Progress under Transition, New York.

World Bank

Land Administration and Management in Ulaanbaatar, Mongolia, Washington DC. 